\title{
Estimating Gross Annual Electricity Demand of Turkey
}

\author{
Mustafa Yavuzdemir ${ }^{1} \&$ Fazıl Gökgöz ${ }^{2}$ \\ ${ }^{1}$ Energy Expert at Energy Market Regulatory Authority of Turkey, Ankara, Turkey \\ ${ }^{2}$ Faculty of Political Sciences, Department of Management, Quantitative Methods Division, Ankara University, \\ Ankara, Turkey \\ Correspondence: Fazıl Gökgöz, Associate Professor Dr., Faculty of Political Sciences, Department of \\ Management, Quantitative Methods Division, Ankara University, 06600 Cebeci, Ankara, Turkey. E-mail: \\ fgokgoz@ankara.edu.tr
}

Received: January 27, 2015

Accepted: February 15, 2015

Online Published: March 25, 2015

doi:10.5539/ibr.v8n4p145

URL: http://dx.doi.org/10.5539/ibr.v8n4p145

\begin{abstract}
The electricity demand has become increasingly significant for the financial decision makers with rapid economic growth. In order to achieve a sustainable economic growth, continuous and adequate power supply is crucial. Due to the electricity is unable to be stored economically and has a characteristic of coincidence of generation and consumption, forecasting electricity demand accurately is of great importance in order to balance supply and demand. Turkey, an emerging market with one of the most rapid economic growth rate in the world, should consider forecasting the gross electricity demand. As it is known, there exists a high correlation between growth rate of gross domestic product $(G D P)$ and electricity demand in developing countries. Therefore, unlike many other forecasting models for electricity demand, a single parameter (GDP in line with the purchasing power parity) has been used to estimate gross annual electricity demand of Turkey in this empirical study. Three different forecasting methods, namely; time series, regression and fuzzy logic techniques have been applied to Turkish electricity demand data and then compared according to the absolute relative errors (AREP). Based on the AREP figures, it can be concluded that time series model has shown a slightly better forecasting performance than the other two methods for estimating gross annual electricity demand of Turkey based on the available data.
\end{abstract}

Keywords: electricity demand, forecasting, fuzzy logic, GDP, Turkey

\section{Introduction}

Due to urbanization and fast economic growth, demand for energy and the necessity of new investments in energy sector have been rising. It's shown in the Table 1 that, International Energy Agency (IEA) indicates, global energy demand in 2035 may be 51\% higher than ones in 2009 .

Table 1. Primary energy demand by fuel

\begin{tabular}{ccccc}
\hline \multirow{2}{*}{ Basis of Energy } & \multicolumn{5}{c}{ Energy Demand (Mtoe) with Current Policies Scenario } \\
\cline { 2 - 5 } Coal & 1980 & 2009 & 2020 & 2035 \\
Oil & 1.792 & 3.294 & 4.416 & 4.419 \\
Gas & 3.097 & 3.987 & 4.482 & 4.992 \\
Nuclear & 1.234 & 2.539 & 3.247 & 9.206 \\
Hydro & 186 & 703 & 368 & 4.054 \\
Biomass and Waste & 148 & 280 & 1.449 & 1.707 \\
Other Renewables & 749 & 1.230 & 256 & 481 \\
Total Demand & 12 & 99 & 12.132 & 124 \\
\hline
\end{tabular}

Source: IEA, 2011. 
Electricity dependence has increased worldwide since last century. The part of electricity in global final energy consumption in 1971 was $9,0 \%, 16,1 \%$ in $2002,17,7 \%$ in 2010 . This rate is expected to reach $20,2 \%$ in 2030 (Yamaçl1, 2010).

In 2011, 239,5 TWh electricity was consumed in Turkey. At first glance, Turkey has still lower per capita consumption levels as it is compared to that of in OECD or EU countries. Per capita electricity production in Turkey was $2.709 \mathrm{kWh}$ in gross terms in 2011 (World Bank, 2013).

Although Turkey has lower per capita consumption (one fourth of IEA average) it is expected to increase as the economy and energy demand grows (Energy Market Regulatory Authority, 2012).

Like in many others, the demand for electricity which has a steady rise in the share of energy consumption is growing in Turkey as well (Table 2). Therefore, so as to achieve high quality and continuous electricity supply, forecasting for short and long term electricity is inevitable for policy makers as well as distribution and transmission companies in Turkey. The results of electricity demand forecasts are also extremely important in order to make adequate energy investment decisions.

Table 2. Gross electricity production and electricity demand $(G W h)$ in Turkey

\begin{tabular}{|c|c|c|c|c|c|}
\hline Years & Gross Electricity Generation & Gross Electricity Demand & Years & Gross Electricity Generation & Gross Electricity Demand \\
\hline 1975 & $15.622,8$ & $15.719,0$ & 1994 & $78.321,7$ & $77.783,0$ \\
\hline 1976 & $18.282,8$ & $18.615,0$ & 1995 & $86.247,4$ & $85.551,5$ \\
\hline 1977 & $20.564,6$ & $21.056,8$ & 1996 & $94.861,7$ & $94.788,7$ \\
\hline 1978 & $21.726,1$ & $22.347,1$ & 1997 & $103.295,8$ & $105.517,1$ \\
\hline 1979 & $22.521,9$ & $23.566,2$ & 1998 & $111.022,4$ & $114.022,7$ \\
\hline 1980 & $23.275,4$ & $24.616,6$ & 1999 & $116.439,9$ & $118.484,9$ \\
\hline 1981 & $24.672,8$ & $26.288,9$ & 2000 & $124.921,6$ & $128.275,6$ \\
\hline 1982 & $26.551,5$ & $28.324,9$ & 2001 & $122.724,7$ & $126.871,3$ \\
\hline 1983 & $27.346,8$ & $29.567,6$ & 2002 & $129.399,5$ & $132.552,6$ \\
\hline 1984 & $30.613,5$ & $33.266,5$ & 2003 & $140.580,5$ & $141.150,9$ \\
\hline 1985 & $34.218,9$ & $36.361,3$ & 2004 & $150.698,3$ & $150.017,5$ \\
\hline 1986 & $39.694,8$ & $40.471,4$ & 2005 & $161.956,2$ & $160.794,0$ \\
\hline 1987 & $44.352,9$ & $44.925,0$ & 2006 & $176.299,8$ & $174.637,3$ \\
\hline 1988 & $48.048,8$ & $48.430,0$ & 2007 & $191.558,1$ & $190.000,2$ \\
\hline 1989 & $52.043,2$ & $52.601,7$ & 2008 & $198.418,0$ & $198.085,2$ \\
\hline 1990 & $57.543,0$ & $56.811,7$ & 2009 & $194.812,9$ & $194.079,1$ \\
\hline 1991 & $60.246,3$ & $60.499,3$ & 2010 & $211.207,7$ & $210.433,9$ \\
\hline 1992 & $67.342,2$ & $67.216,8$ & 2011 & $229.395,1$ & $230.306,2$ \\
\hline 1993 & $73.807,5$ & $73.431,7$ & 2012 & $239.496,8$ & $242.369,9$ \\
\hline
\end{tabular}

Source: TEIAS, 2013.

Furthermore, it is believed that the demand for electricity's continuously increase in the forthcoming years in Turkey. However, this increase in demand is expected to be proportional to the country's economic growth rather than network expansion due to population rise and new settlement areas. In addition to the fact that there is high correlation between GDP growth rate and electricity demand, the former left the latter behind by $1.3 \%$ on average between 2000 and 2011 in Turkey (Figure 1). 


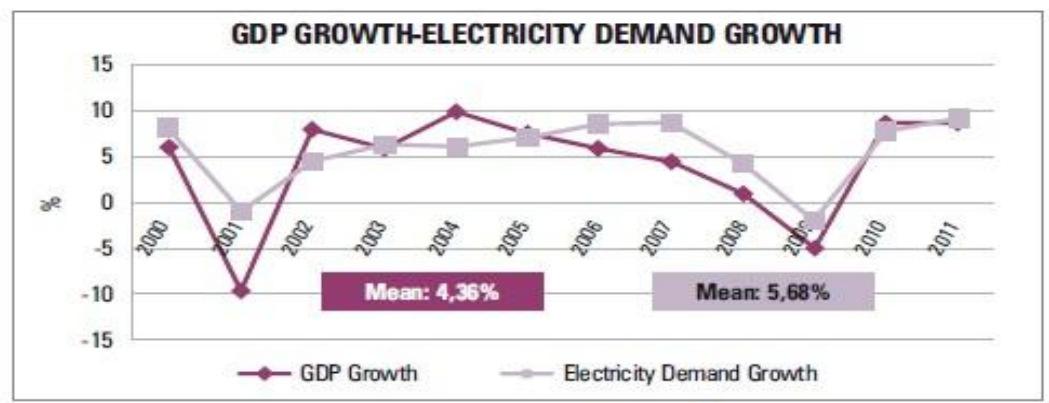

Figure 1. GDP growth rate vs electricity demand growth rate in Turkey

Source: EMRA, 2012.

Empirical studies regarding to estimate electricity demand are still in progress. Alaa El Shazly analyzed the electricity demand using a panel co-integration approach and provided out-of-sample forecasting at the sectorial level. Mattee De Felice, Andrea Alessandri and Paolo M. Ruti performed daily load forecasting for Italy through numerical weather prediction models with the aim of studying the influence of temperature (Felice, Alessandri, \& Ruti, 2013).

On the other hand, Roula Inglesi tried to estimate the electricity demand of South Africa by modelling the Engle-Granger approach of $c o$-integration and Error Correction models (Inglesi, 2010).

Several analysts have also tried to estimate electricity/energy demand of Turkey by models like; Autoregressive Integrated Moving Average (ARIMA) modelling and partial adjustment model (Akay \& Atak, 2007), Grey Prediction with Rolling Mechanism (GPRM) (Hamzacebi, 2007), artificial neural networks (ANN) (Ceylan \& Ozturk, 2005), fuzzy logic approach (Kucukali \& Baris, 2010) and structural time series method (Dilaver \& Hunt, 2011).

GDP is commonly known as the value of all distinguished final goods and services produced in a country during a while of time. In the literature, GDP is defined as the most important element of the electricity demand. Some empirical studies show that energy usage and GDP are combined together in Turkey (Lise \& Montfort, 2007).

Preferring GDP instead of GNP to estimate demand for electricity is more convenient because electricity usage depends on the goods and services generated in the country. Unlike GDP, GNP allocates production based on ownership. The market value of all final goods and services produced annually supplied by the residents of a country is called GNP. As an instance, GDP can be expressed by three different types, namely; fixed, existent prices and purchasing power parity. The GDP values according to purchasing power parity are used in this empirical study.

Determination of adequate and necessary information is the common difficulty in developing a reliable forecast models. Inadequate information leads poor forecasting and useless or redundant information/data makes modeling very hard to construct (Bianco, Manca, \& Nardini, 2009).

A country's electricity demand or consumption can be related to many parameters, such as import, export, population, energy prices or weather conditions. However, in order to construct a simple and practical model, unlike many other models, single parameter model is preferred in this empirical study.

\section{A Short Review of Turkish Electricity Market}

Turkish electricity market was opened to competition in 2001 by electricity market law which was passed by the Turkish Grand National Assembly to begin a new period in the market. The legal framework and design of the new Turkish electricity market was compatible with that of European Union. To accelerate the liberalization process, in 2004, the Turkish government issued a strategy paper, aiming at speeding the liberalization of the electricity market as per the provisions of the law in 2004. Later on, in 2009, the government decided to enact a new strategy paper to accelerate the liberalization process by introducing some measures required for the security of supply. New electricity market law was approved by Turkish parliament on March 14, 2013 and was published in the official gazette on March 30, 2013. One of the most important changes adopted by the New Law is the pre-licensing system. Companies willing to generate electricity have to apply for pre-license first, to operate a generation facility in Turkey.

According to Electricity Market Law and other regulations, any legal company established according to Turkish 
Commercial Law may take place in Turkish electricity market by obtaining appropriate license from Energy Market Regulatory Authority (EMRA). Each activity requires different licenses. Moreover, distinct accounts must be kept by license holders for each and every activity. Tariffs of distribution service of TEDAS, transmission service of TEIAS and electricity selling price of TEDAS are regulated by EMRA according to the Law. For the income of TEIAS, revenue cap is being applied.

By the law, the activities in the market, except for network activities are open to competition under the supervision of, and regulated by EMRA. The electricity market is based on bilateral agreements complemented with the balancing and settlement market. The private sector may participate in all lines of the electricity market, except for transmission, by obtaining the relevant licenses from EMRA. Third party access to the network without discrimination is in place under the supervision of EMRA. The law foresees an independent transmission system operator. According to the law, the ownership, operation, and maintenance of investments in the national grid remain in the hands of TEIAS and TEIAS will remain as the sole transmission system operator and asset owner.

Distribution utilities are responsible for distribution network planning, construction and operation, and for being "supplier of last resort". Distribution companies are entitled to engage in retail business and/or retail sale services for consumers, and generation activities subject to a separate license and accounting unbundling. Distribution utilities unbundled retail activities as end of 2012. Now, distribution and retail sale activities are legally unbundled as of January $1^{\text {st }}, 2013$. New Law also stipulates that distribution companies cannot engage in any activity other than distribution in the electricity market.

Distribution companies have to prepare regional demand forecasts, and submit them to transmission system operator, TEIAS. TEIAS is required by the law to prepare its transmission planning and capacity generation projection based on these demand forecasts and submit them to EMRA for approval. All customers directly connected to the transmission system as well as consumers with consumption of more than $4.500 \mathrm{kWh}$ for 2014 are deemed as eligible customers. The corresponding theoretical degree of market opening is around $85 \%$.

Turkey is giving high importance to the electricity generation from renewable energy sources in order to utilize the domestic sources as much as possible and lower the import dependency on energy sources. For this purpose, a renewable promotion law was enacted in 2005. RES based power plants are supported by feed-in tariff. In addition, up to $1 \mathrm{MW}$ of renewable based power plants are exempted from licensing (Yavuzdemir \& Gozen, 2013).

\section{Literature}

\subsection{Fuzzy Logic Model}

Fuzzy logic attempts to reflect the human way of thinking. The traditional computational logic and set theory is all about true or false, zero or one, black or white (no grey). In reality, two different colors may both be described as "red", but one is considered to be redder than the other. Fuzzy logic can be seen as an extension of ordinary logic, where the main difference is that we use fuzzy sets for the membership of a variable. Fuzzy logic uses fuzzy sets rather than crisp sets to determine the membership of a variable. Lotfi A. Zadeh was announced the fuzzy sets and fuzzy logic in 1965. A fuzzy set can be defined as a collection of objects with graded membership and can be written as below.

$$
A=\left\{\left(x_{1}, \mu_{1}\right) ;\left(x_{2}, \mu_{2}\right) ;\left(x_{3}, \mu_{3}\right) \ldots\right\}
$$

Where A is the fuzzy set, $\mathrm{x}$ the members of the set and $\mu$ is the degree of membership ranging from 0 to 1 (Kucukali \& Baris, 2010). As an example, let "middle age" be defined between 30 and 60. Then, a fuzzy set of middle aged people can be written as;

$$
M=\{(30,0) ;(45,0.5) ;(60,1)\}
$$

According to this set, a man who is 30 or younger is not a middle aged person at all and a man at the age of 45 is somewhat middle aged and a man who is 60 is indeed middle aged.

Fuzzy logic is a method which develops a systematic approach to solve problems in order to control a system while expressing the uncertainty in a system (Kuşan, 2009).

In general, a fuzzy system has five fundamental components which are input parameters such as; fuzzification, fuzzy rule base, defuzzification and outputs. Input parameters should be determined firstly. Then, these have to be divided into fuzzy sets which have fuzzy boundaries with a degree of membership ranging 0 to 1 . The fuzzy sets are classified as low, medium, high, very high etc. The process of translating the measured numerical values into fuzzy linguistic values is called fuzzification. 
In other words, fuzzification is where membership functions are applied, and the degree of membership is determined. Then, fuzzy rules are noted in IF-THEN format based on expert judgment and the data. In further, the results are defuzzified to a certain amount as a conclusion which indicate the correspondent fuzzy set. Defuzzification can be described as a reverse process of fuzzification. Although there are many defuzzification method in the literature, centroid method is the most commonly used one. In this method defuzzification output $\mathrm{Z}^{*}$ is defined by

$$
Z^{*}=\frac{\int \mu(z) z \cdot d z}{\int \mu(z) \cdot d z}
$$

In order to transform the fuzzy set which represent the comprehensive outcome of a certain number (which best represents this fuzzy set) defuzzification is used. (Kucukali \& Baris, 2010).

\subsection{Time Series Model}

A time series model is a series of data points, measured typically at sequential points in time spaced at specific time periods. However, time series forecasting is known as the usage of a model which predicts forthcoming values regarding previously mentioned values. Classical decomposition is another simple technique for describing the series. Time series are classified in the following four different ways (University of Cambridge, 2014):

- Trend $\left(T_{t}\right)$, long term movements in the mean,

- Seasonal Effects $\left(S_{t}\right)$, cyclical changes related to the calendar,

- Cycles $\left(C_{t}\right)$, other cyclical changes (such as a business cycles),

- Residuals $\left(R_{t}\right)$, other spontaneous or systematic changes

A time series can be written in the Equation (4) and Equation (5) which are given in below:

where,

$$
\begin{gathered}
Y_{t}=T_{t} \cdot S_{t} \cdot C_{t} \cdot R_{t} \\
Y_{t}=T_{t}+S_{t}+C_{t}+R_{t}
\end{gathered}
$$

$Y_{t}:$ Observed value at time t;

$T_{t}:$ Trend component at time t;

$S_{t}$ : Seasonal component at time t;

$C_{t}$ : Cyclic component at time t;

$R_{t}$ : Residuals at time t.

Annual time series do not include seasonal effects. In this study all data used are annual data therefore, multiplicative model with no seasonal effect $\left(Y_{t}=T_{t} \cdot C_{t} \cdot R_{t}\right)$ is used to predict future values. In predicting "Trend Component" either linear or quadratic models can be preferred. A linear model can be defined as $t_{t}=b_{0}+b_{1} t$ while a quadratic model as $t_{t}=b_{0}+b_{1} t+b_{2} t^{2}$. Besides, " $\mathrm{b}_{0}$ ", " $\mathrm{b}_{1}$ " and " $\mathrm{b}_{2}$ " are model parameters which can be calculated by least square method. For a linear model,

and for a quadratic model,

$$
\begin{aligned}
\sum y_{t} & =n b_{0}+b_{1} \sum t \\
\sum y_{t} t & =b_{0} \sum t+b_{1} \sum t^{2}
\end{aligned}
$$

$$
\begin{gathered}
\sum y_{t}=n b_{0}+b_{1} \sum t+b_{2} \sum t^{2} \\
\sum y_{t} t=n b_{0}+b_{1} \sum t^{2}+b_{2} \sum t^{3} \\
\sum y_{t} t^{2}=b_{0} \sum t^{2}+b_{1} \sum t^{3}+b_{2} \sum t^{4}
\end{gathered}
$$

are the equations to solve in order to calculate the parameters " $\mathrm{b}_{0}$ ", " $\mathrm{b}_{1}$ " and" $\mathrm{b}_{2}$ " (University of Cambridge, 2014).

\section{Data and Methodology}

Many parameters such as import, export, population, energy prices or weather conditions can be used in order to estimate the electricity amount used or demand of a country. However, single parameter model is used for constructing a simple and practical model in this empirical study.

As mentioned in the earlier parts, GDP is a reliable parameter for Turkey and therefore GDP is chosen as input 
parameter and energy demand is chosen output for the fuzzy model explained in the paper. GDP is a fundamental indicator of a country's economic performance and would be considered by fixed prices, existent prices and in line with purchasing power parity. The GDP data used in our model are in line with the purchasing power parity. Gross electricity consumption data used were collected from TEIAS while GDP data were obtained from IMF.

\subsection{Fuzzy Sets and Rules Used in the Analyses}

The scatter diagram of energy demand vs GDP was used to build up the fuzzy sets and fuzzy rules in fuzzy logic analysis which were carried out in Matlab. The scatter diagram of energy demand vs GDP was also utilized in order to determine the limits of fuzzy sets and the connection between input and output variables. Triangle and trapezoid membership functions are used to represent the fuzzy sets with the maximum contributions as their peaks (Figure 2).
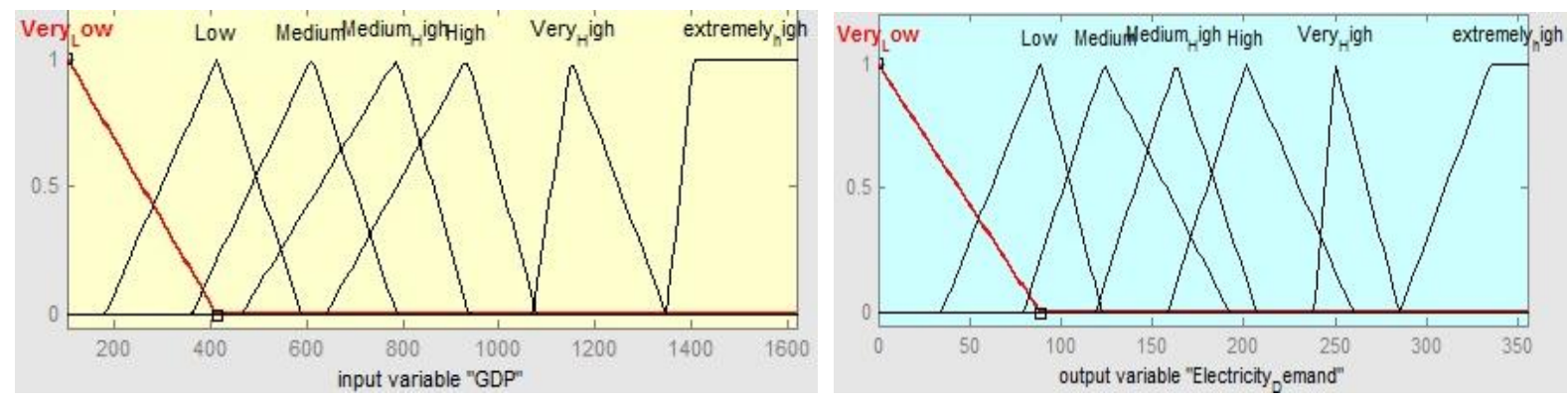

Figure 2. Fuzzy sets for input and output variables

Source: Authors' Calculations in Matlab.

Seven fuzzy rules used in constructing the fuzzy model to estimate the electricity demand in Turkey are given in Table 3.

Table 3. Fuzzy rules constructed for gross annual electricity demand

\begin{tabular}{lllll}
\hline No & \multicolumn{2}{l}{ Rules for the Input } & & Name of the Subset \\
\hline 1 & $I F$ & GDP is Very Low & THEN & Electricity Demand is Very Low \\
2 & $I F$ & GDP is Low & THEN & Electricity Demand is Low \\
3 & $I F$ & GDP is Medium & $T H E N$ & Electricity Demand is Medium \\
4 & $I F$ & GDP is Medium High & $T H E N$ & Electricity Demand is Medium High \\
5 & $I F$ & GDP is High & THEN & Electricity Demand is High \\
6 & $I F$ & GDP is Very High & THEN & Electricity Demand is Very High \\
7 & $I F$ & GDP is Extremely High & THEN & Electricity Demand is Extremely High \\
\hline
\end{tabular}

GDP ranging from 100-1.600 billion US dollars was divided into seven fuzzy sets (Figure 2). In addition, electricity demand ranging from 0-350 TWh was also grouped into seven subsets as "Very low", "Low", "Medium", "Medium high", "High", "Very high" and "Extremely high" (Figure 2). The data were unique for demand of electricity and the structure of Turkish economic. Table 3 summarizes the fuzzy rules used in this empirical study which are consisting of seven fuzzy rules. For a given input, definite IF-THEN rules would be started at the same time. Any rule could have a distinctive power, because a given input can be linked to more than one fuzzy set, aside from same participation values.

In order to clarify the calculation method of gross electricity demand with the fuzzy logic algorithm, GDP $=659$ billion US dollars is taken as input parameter. These input results initiate the Rule-3, Rule-4 and Rule-5. The following parts of the Rule-3, Rule-4 and Rule-5 are then summed up in order to construct a combined output fuzzy subset. Finally, by making use of the centroid method in defuzzification process, the output was calculated by solving the center of mass of the output fuzzy subset. For GDP $=659$ billion US dollars, gross electricity demand was calculated as $147 \mathrm{TWh}$. Results of forecasting studies carried out for Turkish gross annual electricity demand nearby fuzzy logic model, time series model and regression model are illustrated in Table 4. 
Table 4. Results of forecasting gross annual electricity demand of turkey by fuzzy logic model, time series model and regression model

\begin{tabular}{|c|c|c|c|c|c|}
\hline Years & $\operatorname{GDP}(P P P)$ & Gross Demand (TWh) & Regression Model (TWh) & Fuzzy Model (TWh) & Time Series Model $(T W h)$ \\
\hline 1980 & 116 & 25 & 25 & 28,5 & 23,1 \\
\hline 1981 & 133 & 26 & 29 & 28,8 & 25,3 \\
\hline 1982 & 146 & 28 & 31 & 29 & 27,8 \\
\hline 1983 & 159 & 30 & 34 & 29,4 & 30,6 \\
\hline 1984 & 176 & 33 & 38 & 29,9 & 33,6 \\
\hline 1985 & 189 & 36 & 41 & 33,1 & 37,0 \\
\hline 1986 & 206 & 40 & 45 & 37,9 & 40,6 \\
\hline 1987 & 234 & 45 & 51 & 45,7 & 44,5 \\
\hline 1988 & 247 & 48 & 54 & 49,1 & 48,8 \\
\hline 1989 & 257 & 53 & 56 & 51,6 & 53,3 \\
\hline 1990 & 291 & 57 & 64 & 59,3 & 58,0 \\
\hline 1991 & 305 & 60 & 67 & 62,2 & 63,1 \\
\hline 1992 & 330 & 67 & 72 & 67,1 & 68,5 \\
\hline 1993 & 365 & 73 & 80 & 76,3 & 74,1 \\
\hline 1994 & 352 & 78 & 77 & 71,2 & 80,1 \\
\hline 1995 & 385 & 86 & 84 & 87,3 & 86,3 \\
\hline 1996 & 420 & 95 & 92 & 100 & 92,8 \\
\hline 1997 & 460 & 106 & 101 & 107 & 99,6 \\
\hline 1998 & 480 & 114 & 105 & 111 & 106,7 \\
\hline 1999 & 470 & 118 & 103 & 109 & 114,1 \\
\hline 2000 & 513 & 128 & 113 & 117 & 121,8 \\
\hline 2001 & 495 & 127 & 109 & 114 & 129,7 \\
\hline 2002 & 534 & 133 & 117 & 122 & 138,0 \\
\hline 2003 & 574 & 141 & 126 & 133 & 146,5 \\
\hline 2004 & 659 & 150 & 145 & 147 & 155,3 \\
\hline 2005 & 747 & 161 & 164 & 171 & 164,4 \\
\hline 2006 & 825 & 175 & 182 & 186 & 173,8 \\
\hline 2007 & 888 & 190 & 196 & 194 & 183,5 \\
\hline 2008 & 914 & 198 & 201 & 199 & 193,5 \\
\hline 2009 & 877 & 194 & 193 & 192 & 203,7 \\
\hline 2010 & 970 & 210 & 214 & 207 & 214,3 \\
\hline 2011 & 1.075 & 230 & 237 & 230 & 225,1 \\
\hline 2012 & 1.123 & 242 & 248 & 258 & 236,3 \\
\hline 2013 & $1.181^{*}$ & N.A. & 261 & 268 & 247,7 \\
\hline 2014 & $1.249^{*}$ & N.A. & 276 & 279 & 259,4 \\
\hline 2015 & $1.330 *$ & N.A. & 293 & 290 & 271,4 \\
\hline 2016 & $1.417 *$ & N.A. & 313 & 320 & 283,6 \\
\hline 2017 & $1.513^{*}$ & N.A. & 334 & 334 & 296,2 \\
\hline 2018 & $1.614 *$ & N.A. & 356 & 352 & 309,1 \\
\hline
\end{tabular}

Source: Authors' Calculations.

Note. N.A.: Not Available. * IMF projections. 
As can be seen below, Figure 3 illustrates the annual electricity demand values against GDP values including the periods of 1980 and 2012, best fitting regression equation is $E=0,2213$ GDP $-0,8454$.

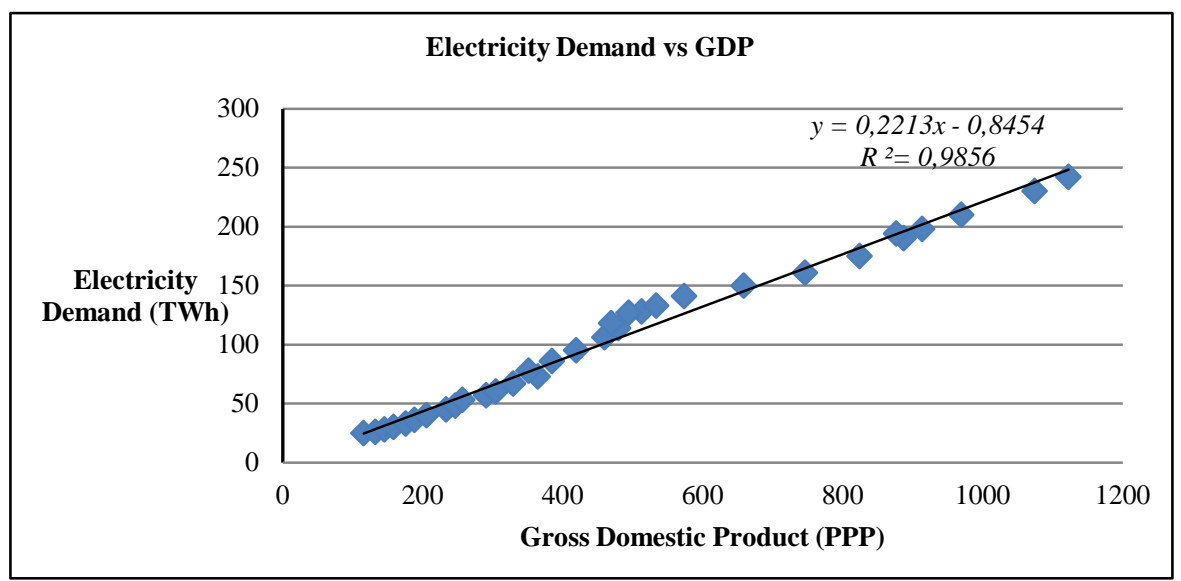

Figure 3. Regression line for electricity demand vs GDP between 1980 and 2012

Source: Authors' Calculations.

Figure 4 shows a comparison of the actual annual gross demand, regression, fuzzy and time series models. Forecasting performance of all techniques was analyzed by average absolute relative errors (AREP). Following Equation (11) was used in order to calculate average absolute relative errors.

$$
A R E P=100(1 / n) \quad \sum \frac{\left|E p_{i}-E m_{i}\right|}{E m_{i}}
$$

In Equation (11), $E_{p}$ and $E_{m}$ are indicated the gross annual electricity demand values, respectively. Based on the AREP values we can say that time series model has better forecasting performance than fuzzy and regression models, since the AREP values are 2,75\%, 4,81\% and 7,64\% respectively. All data computed by these three models are presented in Table 4.

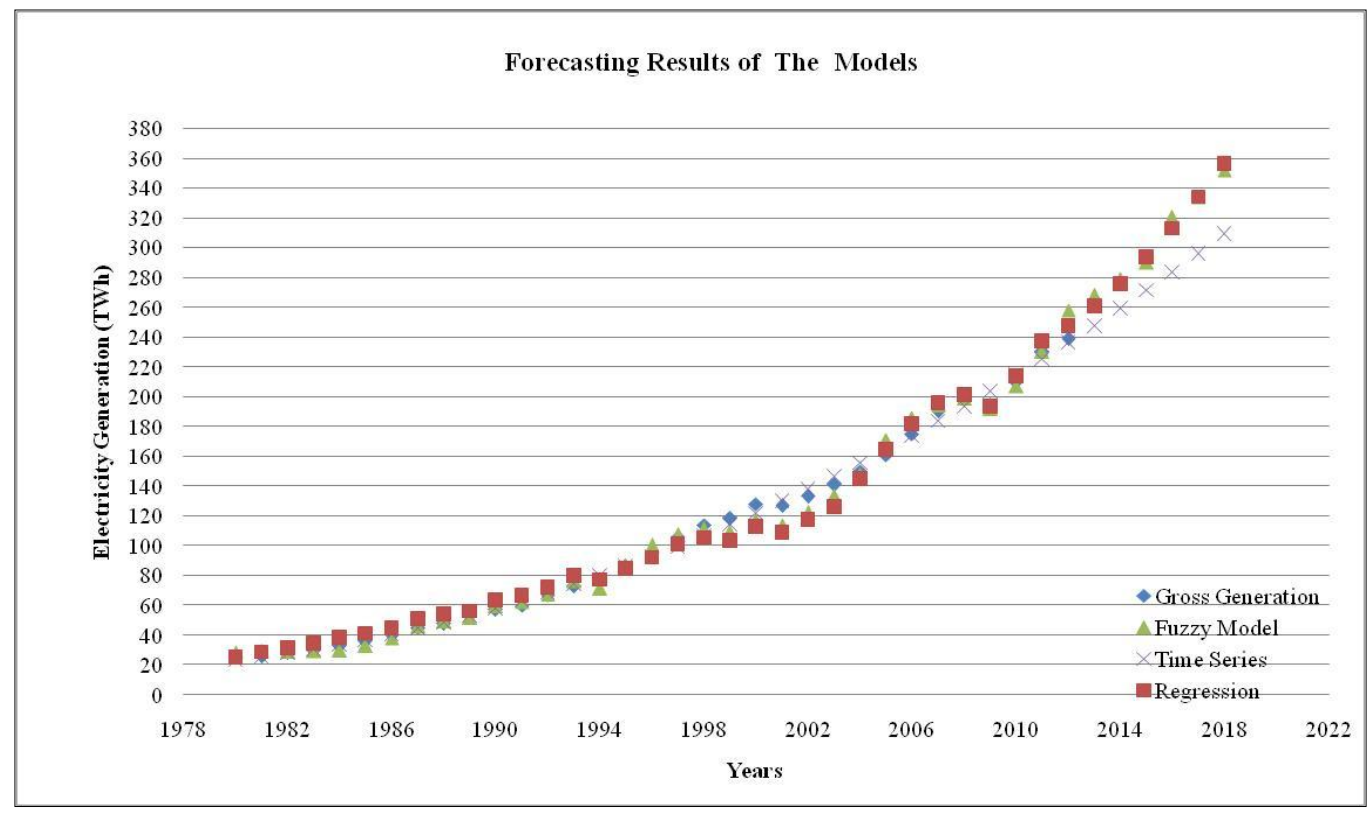

Figure 4. Forecasting results of the estimation models

Source: Author's Calculations. 


\section{Conclusion and Remarks}

Electricity generation market has gained a crucial role in the emerging economies for the last two decades. Since electricity cannot be stored economically and requires high costs, establishing a system meeting the electricity demand with a high quality is vital. Therefore, demand forecasting and production planning studies constitute the most important aspects of electrical system planning.

Many studies dealing with electricity demand forecast reveals that economic growth and electricity demand has a high correlation. In fact, between the years 2000-2011 electricity demand in Turkey grew by 5,68\% on average and over the same period the average gross domestic product increased by $4,36 \%$ on average (Figure 1).

In this paper different forecasting techniques such as fuzzy logic, time series and regression approaches were applied for electricity demand forecasting in Turkey. Results have revealed that electricity demand is strongly related with GDP in Turkey. According to our calculations, one parameter model is sufficient to a certain extent and can be used for electricity demand forecasting of this country.

The advantage of such a model is its simplicity and quick results for policy makers. Based on the average relative errors, we can say that time series model has better forecasting performance than fuzzy and regression models with available data, since the AREP values are estimated as $2,75 \%, 4,81 \%$ and $7,64 \%$ respectively. In order to have more accurate estimation with smaller errors, some other parameters such as import, export, population and energy prices may be included in the models.

In this regard, it can be concluded that the models include trend analyses and fuzzy logic approaches could give significant results in estimating the electricity demand of Turkey and would provide crucial information for decision makers in energy market.

\section{References}

Akay, D., \& Atak, M. (2007). Grey prediction with rolling mechanism for electricity demand forecasting of Turkey. Energy, 32(9), 1670-1675. http://dx.doi.org/10.1016/j.energy.2006.11.014

Bianco, V., Manca, O., \& Nardini, S. (2009). Electricity consumption forecasting in italy using linear regression models. Energy, 9(34), 1413-1421. http://dx.doi.org/10.1016/j.energy.2009.06.034

Ceylan, H., \& Ozturk, H. K. (2005). Forecasting total and industrial sector electricity demand based on genetic algorithm approach: Turkey case study. International Journal of Energy Research, 29(9), 829-840. http://dx.doi.org/10.1002/er.1092

Dilaver, Z., \& Hunt, L. C. (2011). Industrial electricity demand for Turkey: A structural time series analysis. Energy Economics, 3(33), 426-436. http://dx.doi.org/10.1016/j.eneco.2010.10.001

El-Shazly, A. (2013). Electricity demand analysis and forecasting: A panel cointegration approach. Energy Economics, 40, 251-258. http://dx.doi.org/10.1016/j.eneco.2013.07.003

Energy Market Regulatory Authority. (2012). Turkish energy market: An investor's guide. Ankara, Energy Market Regulatory Authority.

Erdogdu, E. (2007). Electricity demand analysis using cointegration and ARIMA modelling: A case study of Turkey. Energy Policy, 35(2), 1129-1146. http://dx.doi.org/10.1016/j.enpol.2006.02.013

Felice, M. D., Alessandri A., \& Ruti, P. M. (2013). Electricity demand forecasting over Italy: Potential benefits using numerical weather prediction models. Electric Power System Research, 104, 71-79. http://dx.doi.org/10.1016/j.epsr.2013.06.004

Hamzacebi, C. (2007). Forecasting of Turkey's net electricity energy consumption on sectorial bases. Energy Policy, 35(3), 2009-2016. http://dx.doi.org/10.1016/j.enpol.2006.03.014

Inglesi, R. (2010). Aggregate electricity demand in South Africa: Conditional forecasts to 2030. Applied Energy, 87, 197-204. http://dx.doi.org/10.1016/j.apenergy.2009.08.017

International Energy Agency. (2011). World energy outlook 2011. Paris, International Energy Agency.

International Energy Agency. (2012). Key world energy statistics. Paris, International Energy Agency.

International Monetary Fund. (2013). World economic outlook database. Retrieved January 14, 2014 from http://www.imf.org/external/pubs/ft/weo/2013/01/weodata/index.aspx

Kucukali, S., \& Baris, K. (2010). Turkey's short-term gross annual electricity demand forecast by fuzzy logic approach. Energy Policy, 38(5), 2438-2445. http://dx.doi.org/10.1016/j.enpol.2009.12.037 
Kusan, H. (2009). Risks assessment in construction projects with fuzzy logic model. Doctoral dissertation, Osmangazi University, Eskisehir, Turkey. Retrieved from https://tez.yok.gov.tr/UlusalTezMerkezi/tezSorguSonucYeni.jsp

Lise, W., \& Montfort, K. V. (2007). Energy consumption and GDP in Turkey: Is there a co-integration relationship? Energy Economics, 6(29), 1166-1178. http://dx.doi.org/10.1016/j.eneco.2006.08.010

Turkish Electricity Transmission Company. (2013). The statics of Turkey electricity. Retrieved January 14, 2014 from http://www.teias.gov.tr/TürkiyeElektrikİstatistikleri/istatistik2012/istatistik\%202012.htm

University of Cambridge. (2014). Statistical laboratory. Time Series. Retrieved January 15, 2014 from http://www.statslab.cam.ac.uk/ rrw1/timeseries/t.pdf

World Bank. (2013). Electric power consumption (kWh per capita). Retrieved January 15, 2014 from http://data.worldbank.org/indicator/EG.USE.ELEC.KH.PC

Yamaçl1, M. (2010). Estimation of long term electricity demand of Turkey. Master's thesis, Dumlupinar University, Kutahya, Turkey. Retrived from https://tez.yok.gov.tr/UlusalTezMerkezi/tezSorguSonucYeni.jsp

Yavuzdemir, M., \& Gözen, M. (2013). Risk analysis of river type hydroelectric power plants: An analysis by using fuzzy logic. Paper presented at the $13^{\text {th }}$ IAEE European Conference, Düsseldorf, Germany. Retrieved from http://www.iaee.org/en/publications/proceedingssearch.aspx

\section{Copyrights}

Copyright for this article is retained by the author(s), with first publication rights granted to the journal.

This is an open-access article distributed under the terms and conditions of the Creative Commons Attribution license (http://creativecommons.org/licenses/by/3.0/). 